\title{
11 The contribution of civil society generated evidence to the improvement of sanitation services in Ghana
}

\author{
Laila Smith, Dede Bedu-Addo, Mohammed Awal \\ and Anthony Mensah
}

\section{Summary}

In Ghana in the wake of government shortfalls, civil society has played a strong role in financing, researching and designing processes and projects for service delivery, unlike many of its African peers. This case study explores the role of civil society tools in showcasing sanitation services at district level, including the I Am Aware initiative (IAA) and the more synthesised District League Table (DLT), promoted through an NGO, the Ghana Centre for Democratic Development (CDD-Ghana). The latter is a tool that provides an overall assessment of social development, ranking all districts across the country. The chapter examines how different stakeholders have used the DLT as evidence for enhancing performance in the sanitation sector. It highlights strengthened evidence use in assessing sanitation performance at the local level: citizens putting pressure on district assemblies for improving performance in sanitation; strengthening avenues for citizen-level engagement, creating a source of pressure at district level; civil society using the evidence for their own project planning; and motivating district assemblies to improve performance.

\section{Background}

This case study explores the role of civil society in the generation and use of evidence in influencing performance in the sanitation sector in Ghana, with a particular focus on the contribution of the I Am Aware (IAA) initiative, drawing on the District League Table (DLT) as the evidence base. Both were promoted through an NGO, CDD-Ghana. While both these tools look at basic services in general, the chapter looks at their role in relation to the sanitation sector in particular. While the IAA and DLT play a valuable role in helping to refine and improve the quality of indicators used to monitor district level performance in sanitation, it is important to recognise they are only a small part of civil society's contribution to move the sanitation sector forward over the past two decades. The concluding part of this chapter will briefly touch on some public engagement tactics used by civil society and how they have cumulatively contributed to positive reforms in the sanitation sector more broadly.

Data collection for this case study took place in late 2018 using qualitative methods involving primary and secondary research, a desk review of published 
documentation on the sector in general, and research and evaluation more specific to Ghana. Thirteen interviews were conducted with selected stakeholders. Two focus group meetings were conducted, including 14 civil society representatives and private sector faecal sludge service providers active in the urban sanitation sector. Further interviews were carried out in January 2019 with district-level government officials at Amasaman in the Ga West Municipal Area of the Greater Accra Region and in April and May 2019 with the Ministry of Sanitation and Water Resource Management and CDD-Ghana.

Limitations of the study included the difficulty in tracking the work of the large number of NGOs contributing to the sector. Their work and achievements are rarely documented (with the exception of reports directly to the donors funding them) and there is no clear mechanism for gathering and disseminating their substantial contributions to sanitation service delivery. This made it difficult to trace how their efforts were contributing to overall progress in the sector performance. However, it was clear that their efforts had brought about significant change in the sector.

\section{Context}

\section{National context}

Ghana was the first African country to gain independence in 1957 . The country is largely decentralised with 16 regions that coordinate the bulk of public services. As at February 2019 Ghana had 260 metropolitan, municipal and district assemblies (MMDAs) that implemented government policies and provided social services at the local level.

Ghana is one of the fastest growing economies in Africa, recently recognised by the IMF as a middle-income country. Ghana's urban population doubled from 1984 to 2013 with growth averaging 3.5\%. Today, the country is one of the most rapidly urbanising countries in Africa with an estimated $54.8 \%$ of the population living in towns and cities (WorldoMeters, 2019). However, many of these people still do not have adequate access to basic services.

\section{The sanitation sector}

Sanitation the world over is a major challenge because of limited political prioritisation and low fiscal commitments, and there is a weak understanding of the factors influencing high-level decision makers to commit to improved sanitation.

In Ghana sanitation provision is fraught with inequities, with the largest gap in access to improved sanitation (WHO/ UNICEF, 2017). The brunt of poor levels of sanitation is borne by the poorest in Ghana, where as recent as 2015 , only $1 \%$ had access to basic sanitation and about $19 \%$ practised open defecation (OD) (WHO/UNICEF, 2017, Ntow, 2019). Almost 57\% of the population use shared latrines - a standard that is below the UN's acceptable levels for promoting safe and effective sanitation

The Joint Monitoring Programme (JMP) established by UNICEF to track country progress towards achieving MDG targets is a universally recognised 
source of evidence for tracking country coverage in water and sanitation. In 2015, the JMP ranked Ghana as the second lowest in the world with 15\% of the population covered by basic sanitation, following South Sudan (Ibid.). This became a point of international embarrassment for Ghana's political leadership and an important catalyst for change, together with the evidence-based advocacy campaigns driven by large INGOs active in Ghana, such as WaterAid, Trend and SNV as well as Coalition of NGOs in Water and Sanitation (CONIWAS), the sector's coalition of civil society organisations. According to the latest available domestic statistics, there has been an improvement of basic provision for sanitation moving from 15\% in 2015 to an estimated 21\% in 2018 (Ghana Statistical Services, 2018).

\section{Institutions and stakeholders influencing the sector}

\section{STATE ACTORS}

Following sustained lobbying from civil society in the lead up to the 2016 elections, President Nana Addo Danquah Akuffo-Addo provided crucial leadership and commitment to driving efforts in addressing the country's challenges in the sector. In January 2017, the Ministry of Sanitation and Water (MSWR) was established, absorbing the functions of the Directorate of the Environmental Health and Sanitation Division (EHSD), which had previously been in the Ministry of Local Government and Rural Development (MLGRD). The MSWR is responsible for policy formulation, harmonisation and coordination of water, sanitation and hygiene (WASH) activities, through its Water Director and Environmental Health and Sanitation Directorate (Appiah-Effah et al., 2019, p. 404). The Ministry also determines key indicators that are tracked by the Ministry of Monitoring and Evaluation.

At district level, Metropolitan, Municipal and District Assemblies (MMDAs) are the basic unit of government and the statutory deliberative and legislative body for the determination of broad policy objectives of the development processes within their jurisdictions (Government of Ghana (GoG), Ministry of Water Resources Works and Housing, 2010). They are responsible for rural, small-town and urban water and sanitation delivery using the private sector for infrastructure planning and delivery, and communities or private operators for management (Respondent 6-Government). They also play the role of regulator, for example, approving tariffs. District assemblies (DAs) are responsible for the planning, implementation, operation and maintenance of water and sanitation facilities and the legal owners of communal infrastructures in rural communities and small towns (Water and Sanitation Monitoring Platform, 2009). Under this authority, District Environmental Health Officers educate communities on sanitation and hygiene and enforce regulations regarding the construction, use, and management of public as well as institutional and household facilities (Respondent 8 - Government).

The EHSD is responsible for sanitation policy-based oversight (Ibid). The ability to provide effective oversight is hampered by inadequate evidence from performance monitoring and annual reports from the National Development Planning 
Commission (NDPC), which are usually published late. The overall responsibility for district performance rests with MLGRD as it carries the human resource responsibilities for the civil service at district level. Embedding similar roles in different ministries at different levels makes coordination a challenge. As indicated by one of the district assembly staff, their dual responsibility to MLGRD and MSWR is difficult as they feel as if their 'head is with MLGRD and legs are with MSWR' (Respondent 1 - Government). Sanitation issues are underreported because most agencies at district level do different WASH activities for which they are not responsible to MSWR. Coordination is particularly problematic with regards to the regulation, monitoring and supervision of private sector service providers.

The Sanitation Ministry is developing its own reporting system to address these coordination gaps (Respondent 8 - Government), but this has been in the making for over a decade. Although most service delivery in the sector at district level has been outsourced to the private sector, government provides little support for their work and consequently has little oversight of their activities (TREND, 2003, Focus group 1). Moreover, where activities are regulated by other agencies, the MSWR has little control over them and may not even receive reports of their activities. For instance, the Environmental Protection Agency, which regulates sanitation provision, is not under the Ministry of Sanitation. This makes coordination of the private sector's work in this area even more difficult (Respondent 3 - Private sector).

Part of the limited performance of sanitation coordination and regulation at the district level is that it has historically been an unfunded mandate. As such, the limited resource allocation for liquid waste in particular at the district level has negatively affected the effectiveness of decentralisation of sanitation service delivery.

\section{NON-STATE ACTORS}

Ghana, unlike many of its African counterparts, is a relatively inclusive society ${ }^{1}$ with a favourable environment for civil society participation in service provision. One underlying reason is the historical leadership that civil society has provided in financing, researching and designing processes and projects for service delivery in the wake of government shortfalls. This was made possible through international donors' ${ }^{2}$ funding of sanitation, predominantly in rural areas, over several decades. The bulk of these resources have been channelled through international non-government organisations (INGOs) and civil society organisations (CSOs).

The state's openness to consultation, debate and engagement has created an opportunity for civil society to play a leading role in moving the sanitation sector forward. This has given civil society legitimacy in the eyes of the state, which has been leveraged to ensure regular and systematised engagement with government in service delivery and polity reform in the sanitation sector.

INGOs and CSOs support government and other agencies in implementation of sanitation programmes through participation in policy dialogue; facilitation of innovation and sharing of best practices; provision of capacity support to community structures; and participation in thematic studies and/or action 
research. They also support collaboration and coordination within the sanitation sub-sector. These international organisations tend to work in partnership with local CSOs at the district level or in collaboration with other national CSOs.

The coordination of these international and local alliances for advocacy purposes is steered through the Coalition of NGOs in Water and Sanitation (CONIWAS), which has been vital in uniting the voice of civil society in the water and sanitation sector. This has been applied in advocacy, lobbying and engagement with the state on policy reform, and mobilising sector actors for actions that are non-confrontational but capable of resolving sector concerns.

A key protagonist for this story is the CDD-Ghana, which is not sectorfocused but rather advocacy-oriented in promoting inclusive participation aimed at strengthening democratic governance and the demand for public accountability in Ghana and Africa. CDD-Ghana was established in 1998 as an independent, non-partisan, not-for-profit research and advocacy think tank. The centre uses research, ideas and partnerships to encourage dialogue to inform and influence public policy and to mobilise citizen engagement at district level on local development issues. A mentioned earlier, this case pays particular attention to two linked interventions by CDD-Ghana for evidence production at district level that have influenced a reform agenda for sanitation and social service provision: the I Am Aware (IAA) campaign leading to the District League Table (DLT) as a source of evidence for this advocacy.

\section{Evidence gaps in the sanitation sector and the need for citizen engagement}

Within Ghana, a key constraint to citizen participation, governmental accountability and responsiveness of public services is limited access to user-friendly, government-produced information on the state, provision and quality of public goods and services (CDD-Ghana, 2017; Respondent 10 - Non-government). The state needs more robust and uniform sources of evidence to continually assess the sector's key policy objectives and improve accountability and investment outcomes at both national and local levels. Meanwhile, from a citizens' perspective, the public needs greater evidence to address weak accountability at the district level and improve district assembly responsiveness to service delivery challenges.

This situation is compounded by weak incentives at all levels of government around the use of evidence. Decision making is often not evidence-based and driven by emotional or political considerations (Twende Mbele, 2019). In addition, availability of data within government entities is constrained due to limited resources and capacities for evidence generation, coordination and use at the district level and upwards. There is weak regulation by the Ministry of Sanitation and Water Resources due to the reliance on evidence from the districts, which themselves have limited capacity to assess performance in sanitation (Respondent $6-$ Non-government). Where evidence is being generated by non-state actors, its use by the state is hindered by bureaucratic rigidities. For example, many civil society actors do not formally register their presence at the district level. Without this registration, the evidence from non-state actors cannot be used by district authorities when collating service delivery data. 
In response to these challenges, over the years various partnerships have emerged between key national, policy and management institutions as well as CSOs to produce and manage data. These partnerships undertake analysis to inform the development of evidence-based human development policy, strategic planning, monitoring and evaluation, and management capacity, and to build the capacity of the citizenry to participate in the development process and take advantage of emerging economic activities (UNDP Ghana, 2019).

\section{Increasing access to evidence in the sanitation sector}

Many state and non-state agencies in Ghana have worked together to use evidence to move the sanitation sector forward. The key champions include UNICEF Ghana, CDD-Ghana, WaterAid, SNV and IRC working with government departments such as MLGRD, Office of the Head of Civil Service, MSWR, the Ministry of Monitoring and Evaluation (MoME), NDPC and MMDAs. Civil society, through its various engagements in generating evidence within the sanitation sector, is an important source of data and engaging in an evidence-informed way through their own respective advocacy efforts and through CONIWAS, as well as through their direct district to national level partnerships.

\section{Bridging the gaps - the IAA and DLT tools}

In 2011, CDD-Ghana began the IAA initiative, a 'non-partisan citizen empowerment tool' established to empower citizens and improve their awareness and engagement with duty bearers by providing free, user-friendly, accessible information on the provision of public goods and services in order to strengthen the demand for public accountability. Working with various partners and government agencies at both national and sub-national level, the project disseminates district-level information focused on service delivery performance through radio, town hall meetings, and the use of SMS text messages (Jones et al., 2019, p. 4). IAA has a data facility centre that helps assemble, archive, and disseminate information related to citizen feedback on service delivery performance through the channels outlined earlier. IAA conducts further analysis of the institutional, accountability and governance context of different services. These are prepared by CDD-Ghana staff and shared locally through fact sheets and briefing reports in local languages with citizens and used for discussions with government officials in live interaction sessions.

CDD-Ghana works with CSO partners who have been trained to work in the regions: each region is covered by one $\mathrm{CSO}$ for two districts per region. These IAA district partners organise Citizens' Social Action Groups (comprising 13 to 15 members each) within each Local Area Council/community group and these citizen accountability-demanding groups are trained on how to analyse data and use it to demand accountability and better services. Other groups include parent/teacher associations (PTAs), farmer-based organisations (FBOs), and women's and youth groups that are representative and inclusive of all zones of the project's districts. They also receive governance and accountability 
literacy training at the local level. The groups then go back to work with their communities to raise awareness on public service delivery issues.

In 2014, CDD-Ghana, through the IAA project, partnered with UNICEF Ghana to design and launch a new social accountability tool dubbed the Ghana District League Table (DLT), previously tested in Latin America, which summarises performance against a set of service indicators at the outcome level. It seeks to improve citizens' access to information about the state, provision and quality of basic public services in order to increase their demand for accountability and to improve responsiveness in service delivery. The DLT also seeks to support government to track development levels across the country and use peer pressure to motivate district assemblies to improve services.

The DLT is an extension of the IAA project concept. While the IAA focuses on sector-based input and output indicators, the DLT focuses on outcome indicators in six sectors: education, health, water, sanitation, security and governance. The information from these six sectors is aggregated into a single index that is used to rank all the districts in Ghana to identify those doing well and those performing poorly. All DLT data is sourced from administrative data provided through the ministries, departments and agencies (MDAs) responsible for the six DLT sectors. ${ }^{3}$ These ministries depend on District Assembly reporting on the state of provision and quality of services generated annually. The data is collected annually and cleaned and processed by CDD-Ghana.

The IAA disseminates the DLT evidence through a website that enables users to compare quality in selected districts. This district level data is presented as graphs. Furthermore, the IAA prepares bulletins that provide infographics that compare the quality of service in particular districts to national averages. A free SMS platform is also set up for citizens to text in requests for data from the DLT, which is sent to them on their phones (Jones et al., 2019, p. 4).

\section{What makes up the sanitation DLT indicator}

The sanitation sector performance indicator used in the DLT is Open Defecation Free (ODF) certification (percentage of communities certified as ODF), as it was a chief concern of both the wider public as well as government. Discussions with CDD-Ghana and the MSWR revealed that the ODF indicator is seen as a multi-sectoral outcome indicator to measure quality of sanitation, with links to health, education and the environment. 'Open defecation free villages' is a composite indicator that is made up of numerous other output indicators relating to systems being in place to keep villages free of visible waste and employing hygiene practices.

For instance, output indicators would monitor latrine construction at the household level, with handwashing facilities with soap or ash close to these facilities, and evidence of handwashing practices being available to ensure hygiene behaviour. These output indicators are tracked by various ministries who carry responsibility for specific elements of the sanitation system. The Ministry of Health engages in the hygiene dimensions of the composite indicator and the 
illnesses that arise from poor hygiene behaviour; the Ministry of Education engages in the mechanisms around awareness-raising associated with hygiene promotion; while the Ministry of Sanitation engages with latrine construction and overall outcome of the composite indicator.

\section{Promoting the use of the evidence from $I A A / D L T$}

A number of interventions were intentionally used in order to promote use of the evidence emerging from DLT. Many of these interventions built relationships, a sense of ownership and trust in the evidence through enabling interaction between evidence users. For example, the use of workshops and regular meetings to engage government at multiple levels around methodological design resulting in ensuring ownership as well as building of relationships and trust. The interventions also strengthened incentives for evidence use - through, for example, using a ranking system and strengthening awareness and understanding of the value of evidence for improving performance. Table 11.1 provides an overview of the use interventions and change mechanisms activated.

\section{Types of evidence use that emerged}

\section{Strengthening capabilities for evidence-based advocacy}

According to a formative evaluation conducted on the IAA, its evidenceinformed campaigns using DLT data have helped strengthen the confidence and capabilities of citizens to engage through civic groups. This has become a pressure point on government actors to improve service delivery, particularly at the sub-national level, and has also inspired citizens to work with district assemblies to use the DLT evidence to monitor the state of service delivery (Jones et al., 2019). In particular, the role of citizens in interrogating the output indicators and engaging with district assemblies on the accuracy and relevance in how they are used has contributed to improving the quality of district level data in the sanitation sector (Respondent 3 - Civil society).

The work done at the ground level through the IAA has helped create more robust evidence for civil society at a national level to use in their advocacy engagements (Jones et al., 2019; Ntow, 2019).

\section{Supporting evidence-informed advocacy for improved service delivery}

The DLT is utilised by CSOs to influence the development of District Medium Term Development Plans and local CSOs use the evidence to convince the district assembly to provide more equitable distribution of national resources to communities living in deprived areas. The Garu Tempane District is a good example of the use of data for advocacy by CSOs. RISE Ghana, a local NGO, and a citizen's group called the IAA Volunteers used district data to put forward a written petition from citizens to the District Assembly. This was successful 
Table 11.1 Evidence use interventions around the IAA/DLT and the changes these influenced

\begin{tabular}{|c|c|}
\hline Evidence use interventions & Effect - change mechanisms activated that enabled use of evidence \\
\hline $\begin{array}{l}\text { Workshop to review the } \\
\text { indicators and to explore } \\
\text { new ones for inclusion } \\
\text { in the DLT performance } \\
\text { assessment }\end{array}$ & $\begin{array}{l}\text { CDD-Ghana and UNICEF organise an annual } \\
\text { methodological review consultative workshop, with } \\
\text { government data-producing agencies at the central } \\
\text { government level responsible for all sectors assessed } \\
\text { in the DLT, to review the indicators and to explore } \\
\text { new ones for inclusion into the DLT performance } \\
\text { assessment. The workshops enable building of } \\
\text { relationships, and create a sense of ownership, } \\
\text { ultimately strengthening evidence uptake from the } \\
\text { findings of the DLT }\end{array}$ \\
\hline $\begin{array}{l}\text { Training of citizen groups } \\
\text { to analyse and utilise data } \\
\text { to demand accountability } \\
\text { and better services as } \\
\text { well as governance and } \\
\text { accountability literacy } \\
\text { more broadly }\end{array}$ & $\begin{array}{l}\text { Increases awareness of the potential of evidence as well as } \\
\text { the ability to analyse and use evidence }\end{array}$ \\
\hline $\begin{array}{l}\text { Active advocacy by CSOs } \\
\text { and citizen groups for } \\
\text { government to support the } \\
\text { use of evidence }\end{array}$ & $\begin{array}{l}\text { Dialogue and engagement processes enable agreement } \\
\text { between and ownership of the evidence by partners as } \\
\text { well as district staff }\end{array}$ \\
\hline $\begin{array}{l}\text { Convening of regular } \\
\text { meetings with sectors at } \\
\text { district level }\end{array}$ & $\begin{array}{l}\text { Interaction with districts allows for the development of } \\
\text { relationships between CSOs and District Assemblies, } \\
\text { therefore strengthening trust in the evidence and } \\
\text { building abilities and confidence of district staff to use } \\
\text { the evidence }\end{array}$ \\
\hline $\begin{array}{l}\text { Annual national launch of } \\
\text { the DLT hosted by CDD- } \\
\text { Ghana and UNICEF and } \\
\text { regional- and district-level } \\
\text { engagements after the } \\
\text { analysis of the report/ } \\
\text { production of the scorecard }\end{array}$ & $\begin{array}{l}\text { The regional- and district-level engagements include } \\
\text { town hall meetings, meetings with government officials, } \\
\text { specific policy planning meetings, e.g. district annual } \\
\text { MTDP planning meetings. These forums engage and } \\
\text { enable citizens in understanding the data for their own } \\
\text { social action together with the media and provide a } \\
\text { space for interaction and engagement with politicians } \\
\text { and sector-based bureaucrats. }\end{array}$ \\
\hline $\begin{array}{l}\text { Providing access to data and } \\
\text { analysis in user-friendly } \\
\text { formats }\end{array}$ & $\begin{array}{l}\text { This allows individuals to understand and relate to the } \\
\text { evidence }\end{array}$ \\
\hline $\begin{array}{l}\text { Presenting the evidence } \\
\text { in comparative formats } \\
\text { through using a ranking } \\
\text { system for districts }\end{array}$ & $\begin{array}{l}\text { Promoting awareness of the evidence and appreciation } \\
\text { of the value of evidence, leading to the improved } \\
\text { institutionalisation of evidence use by making it a part } \\
\text { of professional norms and cultures and thereby creating/ } \\
\text { strengthening motivation for use }\end{array}$ \\
\hline \multicolumn{2}{|l|}{$\begin{array}{l}\text { CDD/UNICEF promoting } \\
\text { DLT uptake to have the } \\
\text { DLT used as an additional } \\
\text { criterion for the DPAT }\end{array}$} \\
\hline $\begin{array}{l}\text { Allocation of national budget } \\
\text { based on the provision of } \\
\text { data and reports }\end{array}$ & \\
\hline
\end{tabular}


in convincing the district to construct a toilet and urinal in the Garu market (Jones et al., 2019).

\section{Influencing district performance management systems}

Evidence from the evaluation of the IAA confirms that the greatest responsiveness to the DLT data is at the district level. Having sampled staff in four districts across Ghana, the IAA evaluation found that these district assemblies have integrated some citizen priorities into their medium-term development plans and that these have commenced service delivery improvements in three of the four districts noted earlier (Ibid., p. 6). The evaluation found that the publicity and pressure around the DLT has been a significant driver for increased district level responsiveness because it created competition and embarrassment among district officials and the space for citizen dialogue on sector data (Ibid.). DAs that perform poorly on the DLT are flagged at national level as 'problem districts', a status that few district authorities want to be labelled with (Respondent 8 - Government).

The DLT has no reward system beyond peer pressure through benchmarking and so districts are not always motivated to respond to its requirements. This is slowly changing, with greater awareness among districts of the links between the DLT and improved district performance (discussed further around the District Performance Assessment Tool (DPAT) system). This awareness raising is also promoted through nationally led campaigns (Wumbel 2017).

\section{Informing planning and budget allocations}

Evidence of civil society use of the DLT can also be found in the IAA evaluation (Jones et al., 2019). The evaluation found evidence that the DLT had been widely disseminated at national level and that most policy and advocacy organisations had used it, and that civil society used the DLT to plan their geographical focus for service delivery interventions, for advocacy at the district level and for policy analysis (Ibid., p. 5). Further evidence through a series of workshops held with national sanitation civil society role players found that the DLT was foundational to the more sophisticated generation of evidence through their service delivery work (Ntow, 2019).

CSOs and citizens use the DLT for advocacy from the district level downwards. The District Performance Assessment Tool (DPAT) is a performance assessment system that relies on the same administrative data that feeds the DLT but is used upwards from the District Assemblies by the MDAs (Government of Ghana, Ministry of Local Government and Rural Development (MLGRD, 2018). The NDPC and MOME noted that the allocation of national budgetary resources by the Ministry of Finance (MoF) is now based on submission of plans, implementation reports and medium-term development plans, certified by NDPC (Respondents 4 and 11 - Government). The growing responsiveness of district assembly officials to how they are ranked through the DPAT system, 
drawing on the same administrative data that feeds the DLT, has helped motivate improved performance. The carrot is the implication of not being able to access further funds from central government if the assessment in the DPAT for the environment, within which the category of sanitation sits, is low. This behaviour change has influenced the structure and process of the public administration by influencing decision making in budgetary allocation at the district level. This, in turn, has led to greater budgetary support from the national treasury for sanitation at district level because districts are performing better in addressing the systems required to increase the number of villages/settlements that are ODF.

\section{Analysing use and the factors that contributed to use}

\section{Interventions undertaken to promote use of evidence}

The IAA campaign, drawing on the DLT evidence, has entailed a series of process facilitation activities that are beginning to produce higher-quality data generation at the district level and greater citizen capacity to hold local government to account for sanitation performance. This has been achieved through CSOs and government stakeholders drawing on deliberate and strategic use interventions to ensure use of the district sanitation evidence that is generated at the local level and fed into national administrative systems. Table 11.1 describes these interventions and the effect they had on individuals, which ultimately resulted in use of the evidence at an organisation and systems level.

The interventions used by the IAA campaign (described in Table 11.1) drawing on the DLT evidence was timely, strategic and effective in enabling evidence use.

\section{Process facilitation}

Enabling dialogue (through workshops, meetings, etc.), for example, allowed district assemblies and CSOs to work together to co-create the methodologies and approaches used to generate the evidence as well as jointly engage in sense-making of the evidence. The trust, relationships, sense of ownership and understanding that emerged through these interactions were important in building capabilities to use the evidence.

While this has been the general sense, there are still some districts that feel there is room for improvement in how the DLT process is integrated into District Assembly assessments used for the DPAT system. This would enable district officials to gain a better understanding of what the criteria for performance assessments are and how these measurements used are used by national institutions.

\section{Knowledge brokering}

As discussed in Chapter 2, linkages between supply and demand of evidence need to be deliberately enabled and supported. Accessing, synthesising and 
analysing as well as disseminating this data through the use of fact sheets, briefs and forums, and training citizen groups was seen as essential in bridging supply and demand at the local level. These functions also essentially served to translate the evidence into an accessible and useful format thereby strengthening the opportunities to utilise evidence.

\section{Institutionalising evidence use}

Formalising the use of evidence through linking it to performance management systems provided incentives and, therefore, motivation for evidence use. CDD and UNICEF, through their efforts to encourage policy uptake and advocacy, are working with MLGRD for the DLT to be used as additional criteria for the DPAT. The use of the DLT as a simple and ready-to-use source of evidence for national performance assessment in sanitation has not yet been institutionalised by MLGRD for use in assessing the performance of district assemblies in relation to sanitation. Nevertheless, two civil society workshops on sanitation indicators held in April and June have indicated that this formalisation is well on its way. ${ }^{4}$

\section{Barriers and enablers of evidence use}

There were multiple barriers and enablers that influenced the success of interventions described earlier and overall evidence use.

\section{Enablers}

At the outset, Ghana had a developed culture of inclusivity with effective platforms and mechanisms for consultation and participation and the support of development partners to promote social accountability, and well-established collaborative relationships between the different stakeholders. This enabled the flow of information and involvement of civil society, notably in the lead up to decision-making processes (Respondent 2 - Non-government). Of importance to the sanitation sector was the presence of CSOs with capacities to assist in addressing challenges.

This provided a receptive environment for changes to the sector advocated for by external influencers (e.g. the eThekwini Declaration by African water and sanitation ministers $)^{5}$ as well as popular pressure from within the country, driven by national coalitions of sanitation NGOs such as CONIWAS (Water Aid Ghana, 2012). However, this may not have been sufficient without the leadership of the newly elected president, who championed the changes necessary to improve the performance of the sector.

The DLT introduced a shift in the types of evidence being generated from input/output levels to outcomes, which better enabled assessment of performance and decision making around service delivery. In addition, the DLT/IAA projects also provided higher levels of brokered knowledge, such as analysing 
the information developing score cards, fact sheets and policy briefs better suited to decision making at the district level.

\section{Barriers}

There continue to be insufficient resources allocated to evidence generation, resulting in gaps in the types of evidence generated, and the data does not cover the entire sanitation chain. For example, there is not enough data collected on transport of waste from the household and how it is treated and disposed of. This is further compounded by inadequate coordination of non-state actorgenerated evidence, which is needed to understand performance at the district level, particularly in urban areas. The limited scope of the DLT indicators being tracked affects the ability to see the overall bigger picture around sector performance.

One of the most significant barriers to the use of evidence in the sanitation sector is staff capacity. Coordinating directors and engineers in the MMDAs all have first and second degrees. In an environmental unit or department, an environmental health officer who does not hold a degree is often 'found wanting' when they come face-to-face with other staff and directors who are degree holders. Psychologically, there is the feeling that they are not at par or co-equals in the workplace (Respondent 8: Government). This negatively affects their capacity to perform their roles, especially when it comes to regulatory oversight at the district level.

Another barrier around capacity is that, although they appreciate the outputs of the projects, many key state and non-state political and social accountability stakeholders, such as Parliament, CSOs and media, lack the capacity to analyse and use the evidence generated by the IAA and DLT projects to inform policy and demand for responsiveness and accountability in public service provision.

Use of evidence is in itself an enabler to evidence use (or conversely in the case of lack of use as earlier discussed). Although public discussion of engagement with DLT evidence through the IAA is heightened around the release of the annual DLT report, it is not sustained until the next round of the report is released (Respondents 9,10-Non-government). This leads to poor use of the evidence or data gathered as people soon forget about the DLT results until the next report is due. Finding social champions to lead advocacy initiatives is needed to sustain the momentum following the national annual launch of the DLT.

\section{Emerging lessons}

\section{How context and intervention influenced the use of evidence}

Overall, it appears that the environment was appropriate for changes in the use of evidence in the sanitation sector. The political milieu was more conducive to inclusion of all stakeholders in the national development process and Ghana 
was making strides in political democracy and social cohesion. To address the historically poor performance of sanitation at district level, UNICEF, development partners and a wide spectrum of national CSOs sought to promote greater social accountability between the state, CSOs, and other partners in improving the performance of the sanitation sector.

Moreover, sanitation was on the rise as an area of focus of increased pressure from civil society. This coincided with increasing use of the DLT to help standardise government's own data on district performance, combined with increasing citizen engagement in making sense of district data and using this to lobby for improved district performance in sanitation. The use of information and communication technology for disseminating the DLT data fit well with the wave of interconnectivity and the current, high use of social media in Ghana. This has made the data generated more user-friendly and easily accessible to all citizens.

Overall, the DLT partnership is working well. However, after four years of implementation, partners are now frustrated because broader resource allocation at national level is still not working well through MOFEP, MDAs and the District Assembly Common Fund (DACF). The partners are, therefore, advocating for the District Development Fund (DDF) to become part of a reward system to serve as motivation for the MMDAs to participate in the DLT. The partners are working with Parliament to query budget allocation and push for better resource allocation. Learning from the National Development Planning Commission's 'carrot' reward scheme with the certification of development plans for the receipt of government budget allocations, may be a good way to ensure wider resource allocation at the national level (Respondent 5 - Non-government).

\section{Strengthening and coordinating the data system}

Ghana has strong, capable national-level CSOs that have played a significant contribution in moving the sector forward. Their contributions on service delivery, however, are limited to the districts where they are funded to work, and therefore the ability to feed these results into a national picture is nonexistent. There has been a long-standing plea from civil society to the Ministry of Sanitation and Water Resources and its institutional predecessors to play this coordinating role so as to be able to better use the various sources of evidence that civil society is generating. The data ecosystem and governance infrastructure in Ghana needs to be strengthened and harmonised to support the production and access to timely, trusted/reliable, relevant data for policy uptake.

\section{Suppliers of evidence need to better understand policy processes}

As civil society players are still significant actors in the delivery of sanitation services, they are also the generators of the evidence stemming from this engagement (Ntow, 2019). As noted earlier, this evidence feeds into their monitoring 
systems, which report to a variety of funders. However, as it is not centralised, it is difficult to gain a broader national understanding of how each project is influencing the progress in systems of delivery.

The systematic practice of evidence use in policy making, analysis and evaluation within and across government and key social actors in Ghana needs to be strengthened. Non-state data producers (CSOs and academia) need to improve their understanding of how, when and which government institutions and other actors use evidence to inform policy design, implementation and monitoring so that they are better equipped to use these opportunities well for improved sanitation services. CONIWAS has been loudest in lobbying the state to address the coordination of data systems highlighted earlier. As a knowledge broker trusted by civil society and the state, CONIWAS could play a valuable role in mentoring civil society in where and when to influence decision making with the evidence they have generated from their service delivery work.

\section{Ownership of the evidence is critical for use}

Developing and building an inclusive culture is paramount in promoting evidence use at all levels of society. Evidence tends to be used when government and key stakeholders are involved in the evidence process from the design stage. Uptake of evidence by government is facilitated when government sees the evidence as part of its developmental objectives in ensuring informed decision making. With reference to non-state actors, community and individual ownership of the evidence process is key in creating the environment for policy mechanisms to work for the desired policy outcomes where these require behaviour change by citizens.

\section{Champions are key}

The role of champions, such as a president, UNICEF, CONIWAS and CDD, when combined can be catalytic in moving a sector forward. This was illustrated in this case study through the President, declaring his support for a particular policy intervention during his presidential campaign through intense lobbying by CONIWAS. Once in power, he then followed through to create and support the mechanisms for it to happen until the desired policy outcomes are achieved. UNICEF's funding of a Ghanaian adaptation of the IAA and DLT has built the tools to benchmark and expose poor performance in the sector at the district level. Government and other stakeholders act speedily when the evidence shames or embarrasses them.

\section{Collaboration requires trust}

Fortunately, the history of an inclusive culture in Ghana has helped build a historically close engagement between civil society as implementors of sanitation, and as such, also valuable knowledge brokers because of their 
own role in evidence generation. This long-standing state dependency on civil society to carry the sector forward, thanks in large part to development partner funding, has been instrumental in creating the foundations for trust between the state and civil society, an uncommon trait in many other African countries. This also calls for improved and increased access to and use of basic indicators for social development. This makes it easier for all stakeholders and citizens to engage with the data as knowledge and use of data/evidence is empowering for all: citizens, government (at all levels) and CSOs. However there needs to be more trust between policy makers and other data producers, users, evaluators (CSOs/think tanks) to facilitate and amplify learning and innovation around the relevance and use of evidence in policy/decision making.

\section{Conclusion}

The IAA campaign and the DLT have begun to effect change in the use of evidence for improving district level performance in sanitation. However, these changes cannot be isolated from broader changes over the last decade with sustained and active engagement by a community of active civil society actors at the national level. These combined efforts have contributed to a series of interventions and investments that demonstrate the state's growing presence in raising awareness through incentive schemes and increasing allocations to this long-neglected sector. ${ }^{6}$

Around the world, many NGOs have demonstrated the ability to undertake high-quality research using results and evidence-based approaches. However, this evidence is not always recognised as credible or legitimate by other actors in accountability processes. The IAA campaign, drawing on DLT evidence, is an illustration of moving beyond this barrier to provide ongoing and sustained evidence that has now become institutionalised within government, at various levels. The need for increased recognition of the potential use of CSOgenerated evidence in policy interventions is a key lesson emanating from this study. In terms of relevance for Africa, the findings from this research will be particularly valuable in informing engagements in addressing institutional barriers around greater use of CSO-generated evidence and advocacy tools for promoting greater prioritisation of sanitation in state decisions around budget and human resource allocations.

\section{Notes}

1 According to the Mo Ibrahim Index IIAG scorecard on Governance, Ghana ranks fifth in Africa on participation and human rights.

2 Notably UNICEF and World Bank.

3 These include Ghana Education Service (GES); Ghana Health Service (GHS); Community Water and Sanitation Agency (CWSA); Ghana Water Company (GWC); Ghana Police Service (GPS); and Environmental Health and Sanitation and Ministry of Local Government and Rural Development (MLGRD). 
4 This progress was confirmed at a meeting between UNICEF, GMEF and the NDPC on 16 December 2019.

5 The eThekwini declaration was part of the second Africasan Conference held in Durban in 2008. Water and Sanitation ministers announced the commitment for a separate budget line for sanitation to enable greater transparency in tracking state resources going towards sanitation as well as an annual budget allocation commitment of $0.5 \%$ of GDP.

6 Including substantive budget allocations by the state towards the government contribution of the second phase of the Greater Accra Metropolitan Area (GAMA) sanitation project, funded through a USD 150 million World Bank loan to the Ghanaian government in 2015; increased budgetary allocations to MSWR; a promotion of the development and use of tools such as the Sanitation Index for all MMDAs; and an award scheme launched by MSWR to reward private sector actors supporting MMDAs in a National Sanitation Challenge programme to successfully implement their liquid waste management strategy proposals.

\section{References}

Appiah-Effah, E., Duku, G., Azangbego, N., Aggrey, R., Gyapong-Korsah, B. and Nyarko, K. 2019. Ghana's post-MDGs sanitation situation: An overview. Journal of Water, Sanitation and Hygiene for Development, 9, 3.

CDD-Ghana. 2017. Ghana's district league table report 2017. Retrieved 6 November, 2018, from www.iamawareghana.com; www.cddgh.org/publications

Ghana Statistical Service. 2018. Snapshots on key findings, Ghana Multiple Indicator Cluster Survey (MICS 2017/18). Survey, Findings Report, Accra, Ghana.

Government of Ghana, Ministry of Local Government and Rural Development (MLGRD). 2018. District performance assembly tool: Operational manual. Retrieved from www.mlgrd. gov.gh/ctn-media/filer_public/b1/d2/b1d2f2c0-66fb-4f1a-9366-bfc169e49396/2018_ dpat_operational_manual.pdf

Government of Ghana (GoG), Ministry of Water Resources Works and Housing (MWRWH). 2010. Water and sanitation sector performance report. Retrieved 20 March 2019, from www. washghana.net/.../Final_2010_Sector_Performance_Report[1].pdf

Jones, E., Amidu, I. and Nyarko, C. 2019. Formative evaluation of the 'I Am Aware' social accountability project in Ghana. Oxford, UK: Oxford Policy Management Limited.

Mo Ibrahim Index. 2018. Retrieved from http://s.mo.ibrahim.foundation/u/2018/10/ 26173830/2018-IIAG-scorecard-GH.pdf

Ntow, S. 2019. Baseline report: Sanitation status in Ghana and the role of CSOs in the policy processes. Report Commissioned by Twende Mbele.

Progress on Drinking Water, Sanitation and Hygiene. 2017. Update and SDG baselines. Geneva: World Health Organization (WHO) and the United Nations Children's Fund (UNICEF). Licence: CC BY-NC-SA 3.0 IGO.

Trend Group. 2003. Water, sanitation and service delivery in Ghana, Ghana. Retrieved 20 March 2019, from www.ircwash.org/sites/default/files/WELL-2003-Water.doc

Twende Mbele. 2019. MEE culture baseline study. Ghana: Executive Summary.

UNDP. 2019. Promoting inclusive growth and development. Retrieved from www.gh.undp.org/ content/ghana/en/home/operations/projects/poverty_reduction/all-projects.html

World Health Organization (WHO) and the United Nations Children's Fund (UNICEF), 2017. Progress on Drinking Water, Sanitation and Hygiene: 2017 Update and SDG Baselines. Geneva. Licence: CC BY-NC-SA 3.0 IGO.

Water Aid Ghana. 2012. CSOs' assessment of Ghana's e Thekwini commitments compiled by Ibrahim Musa, Economic Impacts of Poor Sanitation in Africa, UNDP-Water E Sanitation Program 
Report, March 2012. Retrieved from https://washwatch.org/uploads/filer_public/86/ d2/86d2ad38-ae52-4e77-bf3c-36c68cc39d75/cso_ethekwini_assement_-_ghana.pdf

Water and Sanitation Monitoring Platform. 2009. Status of Ghana's drinking WES sector. Country summary sheet. Ghana. Retrieved 18 March 2019, from www.wsmp.org/down loads/country-summary-sheet-09.pdf

WorldoMeters. Retrieved 14 April 2019, from www.worldometers.info/world-population/ ghana-population/.

Wumbel, A. Every day is sanitation day. Retrieved 28 November 2017, from www.ircwash. $\mathrm{org} /$ news/every-day-sanitation-day 